\title{
Differences in Work Attitudes When Nurses Get Their Ideal Roster Based on Their
}

Shift Preferences

\begin{abstract}
Background: Unattractive work schedules can be a cause of discontentment for nurses. Moreover, optimizing the fit between nurses' preferences in shifts and obtaining and securing organizational goals, is very complex.

Aims: To gain insight into (1) the preferences in shifts of individual nurses and (2) the discrepancy between the "imposed roster" (drawn up by the manager or head nurse) versus the “nurses' ideal roster" (ideal for the individual nurse, without regard to any restrictions) through four work attitudes, i.e. autonomy, job satisfaction, work-life balance and employer attractiveness.
\end{abstract}

Method: An exploratory cross-sectional pilot study where the focus lies on descriptive statistics rather than formal hypothesis testing.

Results: The results showed a significant difference in the mean score of nurses' their autonomy, job satisfaction, and work-life balance when the "nurses' ideal roster" would be used. Nurses' preference in shifts were mapped into three groups with similar preferences. Two cluster groups showed a significant higher median autonomy, work-life balance and job satisfaction in case of the nurses' ideal roster. These groups showed no large differences with regard to their personal characteristics.

Conclusion: This pilot study already indicates that nurses' ideal roster can lead to better work attitudes, and that groups of people exist with differences in shift preferences. The next step is to perform more advanced analyses in newly collected data, which aim to account for common method bias, clarify the characteristics of the different groups and take the discrepancy between the two rosters into account. 
Key words: Workforce Scheduling, Flexible work arrangements, Nurse, Self-Scheduling, Nurses' Ideal Roster, Temporal Structure, Entrainment

\section{INTRODUCTION}

Many studies, policy makers, governments, and practitioners address the issue of understaffing of nurses (Glette, Aase, \& Wiig, 2017). The need to avoid this understaffing is high, especially considering negative outcomes of suboptimal staffing, such as poor or failing patient safety and higher inpatient mortality (Aiken et al., 2012; Aiken et al., 2014). While the motivation of nurses for this profession is strongly linked to the occupation itself, the short-staffing impacts the satisfaction of nurses leading to higher burnout and turnover rates (Aiken, Clarke, Sloane, Sochalski, \& Silber, 2002; Boamah, Read, \& Spence Laschinger, 2017). Poor work environments, high workloads and unattractive work schedules are the main causes of this discontentment (Cline, Reilly, \& Moore, 2003). This could lead to a trickle-down effect: if the monthly schedule causes a poor work-life balance, nurses become unsatisfied with their schedule, they become dissatisfied with their employment, and may leave the organization. This puts increased strain on the remaining staff, which - in its turn - will affect scheduling problems and the satisfaction and retention rates of the remaining personnel. In response, nurses' shift preferences and the search for the best fit between these preferences and the organizational goals, receive increasing attention (Bard \& Purnomo, 2005).

Optimizing the fit between personnel preferences and obtaining and securing organizational goals through nurses' rosters, is very complex. We identify four main challenges: (1) determination of appropriate nurse staffing levels and measurement of workload is difficult given variation in patient demand and acuity of patient illnesses, (2) the different levels and sets of skills and experiences among employees, (3) the strict rules and regulations with regard to scheduling, and (4) the high number of different possible schedules. In order to break down the complexity of the nurse scheduling problem, different perspectives have already been discussed 
in previous research. For example, various authors have proposed a categorization of personnel planning into three hierarchical phases, i.e. the long-term strategic staffing phase, the mediumterm tactical scheduling phase and the short-term operational allocation phase (Abernathy, Baloff, Hershey, \& Wandel, 1973; Burke, De Causmaecker, Berghe, L, \& eghem, 2004). On the other hand, Khoong (1996) proposes a generic manpower system framework with six decision layers, i.e. (1) strategic planning through analysis of trends, (2) long-term organizational strategic planning, (3) short term organizational tactical planning, (4) individualized tactical planning, (5) individualized operational planning, and (6) manual execution (Khoong, 1996). In both perspectives, the long-term allocation decision process distinguishes itself from the mid- or short-term workforce scheduling where a decision per month or even per week is made. Rostering itself generally refers to the short-term timetabling of staff, i.e. with a time horizon of a few weeks (Burke et al., 2004). It can be defined as "the placing, subject to constraints, of resources into slots in a pattern. One may seek to minimize some objective, or simply to obtain a feasible allocation. Often the resources will rotate through a roster" (Wren, 1995) and can be seen along two perspectives: the organization on the one hand, and the employee on the other hand.

From the perspective of the organization, efficient workforce scheduling around the clock is needed to minimizes labor costs while safeguarding high-quality levels of nursing care and guaranteeing an optimal nurse-patient ratio. On top of that, the hospital also needs to take into account policy and regulations related to shift work (Venkataraman \& Brusco, 1996; Wynendaele, Willems, \& Trybou, 2019). This makes scheduling and formatting of rosters a very difficult and complex task for nursing management (Burke et al., 2004; Hung, 1995).

From the perspective of the employee, the quality of the roster is often measured in terms of satisfying the individual preferences, which can be seen as part of a good nursing work environment (Ernst, Jiang, Krishnamoorthy, \& Sier, 2004). Shift preferences can play an 
important role in different work attitudes, such as job satisfaction and work-life balance. However, these preferences will differ per individual given the diversity in priorities according to the different life stages (e.g., taking care of children), or the variety in personal characteristics (e.g., morning versus evening type persons). For example, often young parents or grandparents like to have time off on Wednesday afternoons. As a consequence, there will exist differences with regard to individual preferences for certain shifts. However, this perspective received less attention compared to the perspective of the organization.

The perspective of the organization and the perspective of the employee appear to be intertwined. In this regard, the degree to which an employee goes along with or adapt to the nursing schedule, which can be considered as a temporal structure of the organization, may differ (Ancona \& Waller, 2007; Perlow, 1999). Although the work patterns of nurses are steered by the rhythm of the schedule in which they become embedded (Ancona \& Chong, 1996; McGrath \& Kelly, 1986), the question remains to what extent the temporal structure of the nursing rosters on organizational level synchronizes with the individual temporal schemata of the employees.

\section{Nurses' ideal versus imposed roster}

As a consequence of the rostering challenge, different types of rostering approaches have been explored; for example, departmental rostering, team rostering, and self-rostering (Silvestro \& Silvestro, 2000). The contemporary solutions have mainly been addressed from the organization's perspective and therefore neglects the individual perspective and the perspective of the interaction between the individual and the organization. However, there is a growing awareness of the importance of time in organizations as employers seek to coordinate and synchronize employee's behavior (Nguyen Huy, 2001). Entrainment, i.e. "the process that captures or modifies human activity cycles and sets these cycles oscillating in rhythm with other processes, including various social systems, norms and intuitions" (McGrath, Kelly, \& 
Machatka, 1984; McGrath \& Rotchford, 1983), can facilitate this exploration. Often, employees fall into the rhythm and tempo of the temporal structure of the organization (Ancona \& Chong, 1996). However, this entrainment appears to be imperfect and will likely differ from individual to individual. A recent conceptual study on entrainment versus resistance of employees to the temporal structures of their organization, advances theory regarding individual temporal schemata (i.e., cognitive frameworks about time) enabling interpretation of employees' reaction to temporal cues (Shipp \& Richardson, 2019). This study highlights the underdeveloped individual-level aspects of entrainment, which is crucial to predict if organizational efforts to coordinate individual behaviors will succeed or fail. For example nurses can entrain with or resist to an imposed nursing roster. If this roster does not match with the individual temporal schemata of a nurse, this could lead over time to negative working attitudes such as dissatisfaction and even absenteeism or resignation. It is therefore necessary to identify how individual employees compare their own individualized view of time versus the temporal structure of the organization.

In this article, we will use the term "roster" to refer to the planning period over which the nurses have to be scheduled. The "ideal roster" can be ideal from the perspective of the organization, from the perspective of the nurses or can be the result of a good compromise between both perspectives. In this article, however, we will mainly look at the "nurses' ideal roster", by which we mean that the roster is ideal for the individual nurse, without regard to any restrictions. In addition, this roster will consists of separate shifts, e.g. the traditional morning, evening and night shift. When we look at the nurses' ideal roster, we therefore look at the "shift preferences" for the entire planning period. The imposed roster, on the contrary, is the traditional planning of a roster by one single manager or head nurse also known as "departmental rostering" (Silvestro \& Silvestro, 2000). 


\section{The Link between Rosters and Work Attitudes}

Increasingly, healthcare organizations move away from the "imposed roster" and as a response, flexible work arrangements are gaining popularity (Jeffrey Hill et al., 2008), especially those that reflect the choice of nurses. These flexible work arrangements seem to fulfill both the goal of the organization to be an attractive employer, whilst at the same time also promoting an increase in autonomy for the employees, leading to higher job satisfaction, work-life balance and retention in the nursing staff (Albertsen, Rafnsdóttir, Grimsmo, Tómasson, \& Kauppinen, 2008; Eby, Casper, Lockwood, Bordeaux, \& Brinley, 2005; Koning, 2014; Storey, Cheater, Ford, \& Leese, 2009). In other words, by giving employees more autonomy, they will be more inclined to translate this in positive work attitudes (Ryan \& Deci, 2000). Social exchange-based constructs are often used to explain desired work attitudes and behavior. According to the social exchange theory (Blau, 1964), when an organization treats an employee in a positive way (e.g., by taking into account their preferred working hours), this employee, in return, will tend to reciprocate with more positive attitudes and behaviors (e.g., less inclined to leave the organization) (Cropanzano \& Mitchell, 2005). One example of a flexible work arrangement is self-scheduling; a system that moves the responsibility of creating a work schedule to the employees, giving them more control over their work hours (Asgeirsson, 2014). In recent years, there has been a growing interest in self-scheduling (Albertsen et al., 2014), primarily because this method makes it possible that nurses themselves have a personal involvement in the development of their schedule. That is, the individual employees can ask for their personal preferences in shifts each month. More specific, at the start of each month, employees express their "ideal roster", i.e. without regard to any restrictions such as required number of FTE nurses per shift. In the next phase, all individual schedules are integrated and all employees collectively - as a team - switch shifts to meet the staffing needs (Ronnberg \& Larsson, 2010). Furthermore, while self-scheduling, in itself, has good intentions by giving 
more autonomy to the employee, the monthly procedure is often seen as a cumbersome process (Silvestro \& Silvestro, 2000). All this means that the "final roster" may differ to some extent from the "nurses' ideal roster".

In the search of the nurses' ideal roster, insight into the individual preferences of the nurses is crucial. These shift preferences have hardly been studied in a detailed manner, which makes them hard to incorporate in the roster. This leads us to the first research question: "Which nurses' preferences in shifts can be identified?". In addition, scheduling research has, to the best of our knowledge, never looked into the differences in work attitudes between the "nurses' ideal roster" versus any other method of rostering. As a consequence, the second research question explored the difference in work attitudes between two types of rosters: "Are there differences in work attitudes between the "imposed roster" versus "nurses' ideal roster"?. The third research question goes into more detail by also taking into account the preferences in shifts: “When looking at the nurses' preferences in shifts, are there differences in work attitudes between the "imposed roster" versus "nurses' ideal roster?".

\section{Aim of this Study}

This study focuses on the discrepancy between the "imposed roster" (drawn up by one single manager or head nurse) versus the " nurses' ideal roster" (ideal for the individual nurse, without regard to any restrictions) for nurses in hospitals. It links this this discrepancy through four work attitudes (autonomy, job satisfaction, work-life balance and employer attractiveness). In addition, the preferences in shifts of the individual nurses are mapped into groups and within these groups, the link between the discrepancy in rosters and the four work attitudes is again made. More specific:

(1) We look at the potential differences in autonomy, job satisfaction, work-life balance and employer attractiveness when an employee would get his or her ideal roster versus their imposed roster; 
(2) We gain insight into the nurses' preference in shifts and map these nurses in groups so that observations within a group are relatively similar;

(3) Within these groups of nurses with similar individual preferences, we look at the potential differences in autonomy, job satisfaction, work-life balance and employer attractiveness when an employee would get his or her ideal roster versus their imposed roster.

\section{Conceptual Model}

We link the social exchange theory to autonomy, expecting that when employees have more autonomy, they reciprocate by changing their work attitudes towards the organization. An employee that is given the opportunity to create his or her own ideal schedule (increased autonomy), will have a better work-life balance (Albertsen et al., 2014; Pryce, Albertsen, \& Nielsen, 2006), which may lead to a higher job satisfaction (Koning, 2014; Mas-Machuca, Berbegal-Mirabent, \& Alegre, 2016). In addition, an increased autonomy could also result in a higher employer attractiveness, which strengthens the relationship between both parties and safeguard commitment (Onken-Menke, Nüesch, \& Kröll, 2018). This, in turn, could result in additional recognition by the healthcare organization that, consequently, could renew the employee's desire to reciprocate. Next, we built further on this social exchange theory by including the individual temporal schemata of the employees (Shipp \& Richardson, 2019) via the nurses' ideal roster, which means that we include his or her personal preferences in shifts. The organizational temporal structure is represented by the imposed roster. Here, we assume that, when employees can follow their own individual temporal schemata, this will have a positive association with our predefined work attitudes. Figure 1 provides a simplified graphical representation of these hypothesized associations. 
Insert Figure 1 about here

Finally, given that our study is a pilot study, the obtained data will not be used for hypothesis testing. Instead, it serves as an early-phase developmental study that will enhance the probability of success in a lager anticipated multicenter study. For this reason, the focus will be on descriptive statistics (and confidence interval estimation) rather than formal hypothesis testing (Lancaster, Dodd, \& Williamson, 2004).

\section{METHOD}

\section{Study Design, Setting and Participants}

In this cross-sectional pilot study, a survey was distributed to 384 nurses and midwifes between October-December 2019 in a large University Hospital in Belgium. The wards in this hospital were chosen at random and all employees worked with a fixed monthly imposed schedule (= traditional cyclical schedule) made by the head nurse. We obtained approval from the Medical Ethics Committee of [removed for review process].

\section{Measurements}

First, to capture the preference in shifts, a schedule for June 2019 (four weeks) was incorporated in the survey.

Ideal schedule. This represents the ideal schedule for the employee, i.e. without regard to any restrictions such as required number of FTE nurses per shift. To facilitate this, the participants could choose between morning, evening and night shifts. These are common shifts in the hospital and were also used by the head nurse for drawing up the schedule. This roster consisted of 28 days $\mathrm{x} 3$ shifts $=84$ different dichotomous variables (working versus not working). For each day, the employee could choose a maximum of one shift. For example, for Monday, June 32019 , one could enter: morning shift "not working", evening shift "working", nigh shift "not- 
working". The total number of shifts at the end of the month had to be the same as stipulated in their contract with their employer. For further analysis of this data, the sum of preferred shifts per day was used ( 7 days $\mathrm{x} 3$ shifts $=21$ different count variables $)$.

Next, employees were asked to score several work attitudes considering two situations: one for the schedule they had received from the head nurse in June 2019 ("imposed roster", and one for their (theoretical) "nurses' ideal schedule" in that same month. For this reason, the following previously validated and published concepts were translated in Dutch using forward-backward translation (Beaton, Bombardier, Guillemin, \& Ferraz, 2000):

Autonomy. The Work Scheduling Autonomy scale is part of the larger Autonomy scale created by Breaugh (1985) and consists of three items. We used a 5-point Likert scale ranging from one (totally disagree) to five (totally agree). For example, "I have control over the scheduling of my work"; is one of the three items.

Work-life balance. The Work-Life Enhancement By Work subscale of the larger Work Life Balance scale was used (Rincy \& Panchanatham 2010). This subscale includes seven items, for example "My job keeps my personal/family life enjoyable". A 5-point Likert scale was used, ranging from one (totally disagree) to five (totally agree)

Job satisfaction A single-item instrument for job satisfaction was used, with a 10-point Likert scale ranging from one (extremely dissatisfied) to ten (extremely satisfied). Previous studies reported that this single-item has a high reliability and good concurrent and construct validity (Dolbier, Webster, McCalister, Mallon, \& Steinhardt, 2005).

Employer attractiveness. The General Attractiveness scale is a subscale of the Organizational Attraction scale by (Highhouse, 2003). Five items were asked on a 5-point Likert scale ranging from one (totally disagree) to five (totally agree). An example of one of the items is: "For me, this company would be a good place to work". 
Finally, the survey included several baseline characteristics such as gender, age, marital status, number of children, function and work regime.

\section{Statistical Data Analysis}

$\mathrm{R}$ version 3.6.3 was used to perform the statistical analysis. First, baseline characteristics are presented to assess the relevant variables and lifestyle characteristics of the employees. In addition, Student's paired t-test was used to determine whether the mean difference for the selected work attitudes between the two predetermined situations (imposed versus nurses' ideal roster) were significant.

Second, dimensionality reduction was performed given the high number of predictor variables for the nurses' ideal roster ( 7 days x 3 shifts $=21$ different count variables). Assuming that this count data has a negative-binomial distribution, an inverse hyperbolic sine transformation was used (Burbidge, Magee, \& Robb, 1988; Nguyen \& Holmes, 2019). Subsequently, a principal component analysis (PCA) was performed using the R package FactoMineR (Le, Josse, \& Husson, 2008) on the nurses' ideal roster data to investigate the pattern of associations between the shift variables. PCA is used to summarize the 21 variables by seeking a small number of components that explain maximal variance in the observed data. These components are linear combinations of the original variables and are uncorrelated with previously extracted components. This makes it possible to study the patterns of association, even though the observed variables are correlated with each other. In this way, a taxonomy of shifts can be created, i.e. which shifts are preferred by the same employee, via interpretation of the component loadings. The latter can be understood as the weights for each original shift variable when calculating the principal component. These loadings make it possible to see which employees load on the same component and can then be classified as having the same preferred shift preference. A scree plot (visualization of the eigenvalues of the components versus the number of the components) and Kaiser's rule (retain only components with eigenvalues greater 
than 1) were used to determine how many components should be retained. For visualization purposes, biplots will give a low dimensional presentation of this data, presenting both the employees as the shift variables.

Third, a cluster analysis was performed using the R package FactoMineR (Le et al., 2008). The goal of this unsupervised method is to divide the observations into groups of employees so that observations within a group are relatively similar and observations of different groups are dissimilar. We used a two-stage approach. First, a hierarchical clustering on squared Euclidean distances with the method of Ward on the selected principal components. Ward criterion is used in this clustering because it has a tendency to produce equal-sized clusters that are convex and compact. The dendrogram is used to detect multivariate outliers (i.e. small clusters formed at the end of the clustering process). Next, k-means clustering is performed with centroids of hierarchical clustering as starting points.

Finally, the different clusters (i.e. groups of employees with similar preference in certain shifts) are described using their baseline characteristics. In addition, Wilcoxon one-tailed signed rank test is used to compare the two predetermined situations (imposed versus nurses' ideal roster) in relation to the selected work attitudes and this for each small sample size cluster. Here, the assumption is already made that it is more likely that the nurses' ideal roster will have a higher median than the roster drawn up by the head nurse.

\section{RESULTS}

\section{Baseline Characteristics}

In total, 101 surveys were gathered, of which 58 surveys had complete data for the nurses' ideal schedule. These 58 surveys were used to conduct further analysis (overall response rate of 15 $\%)$. The majority of the employees worked full-time (55\%) versus part-time (45\%). For the part-time workers, most employees are female (96\%), were married or living together (84\%) 
and had children (72\%). The full-time workers have a similar profile, though small differences can be spotted. For example, the proportion of males (25\%) and divorced or single people (34\%) is higher than for the part-time workers. In addition, fewer people have children (31\%) and the mean age is lower (33 versus 41 year). Table 1 gives a summary of the employee's characteristics per work status (full-time versus part-time).

Insert Table 1 about here

\section{Ideal versus Imposed Roster: Main Differences}

Table 2 provides an overview of the mean difference in work attitudes (autonomy, work-life balance, job satisfaction and employer attractiveness) between the situation where the roster is created by the head nurse (imposed roster) versus the situation where the employee makes his or her own schedule (the nurses' ideal roster). This shows, for example, a significant difference in the mean score for autonomy (mean difference $=0.67,95 \%$ CI $[0.45$ to 0.90$]$ ) when the nurses' ideal roster would be used compared to the imposed roster ( $\left.\mathrm{t}_{55}=6.01, \mathrm{p}<0.001\right)$. All the other work attitudes show the same significant differences in mean score, except for employer attractiveness which shows a non-significant $\left(\mathrm{t}_{54}=2.18, \mathrm{p}<0.033\right)$ difference (mean difference $=$ $0.16,95 \%$ CI [0.01 to 0.30]), after applying the Bonferroni correction.

Insert Table 2 about here

\section{Nurses' Preference in Shifts}

Next, we take a look at the nurses' preferences in shifts, as an expression of their individualized view of time that is recorded in their individual temporal schemata. 


\section{Principal component analysis}

The ideal schedule for the employees for one month was merged into 21 different predictor variables ( 7 days $\mathrm{x} 3$ shifts $=21$ different count variables). Using the dimensionality reduction method "principal component analysis", two principal components were retained based on Kaiser's rule and the scree plot (cf. Figure 2).

Insert Figure 2 about here

These two principal components account for $54.94 \%$ of the variance in the 21 variables, where the first component alone accounts for $30.72 \%$ of the variance. This is shown in Table 3, which also provides the components loadings, i.e. which shifts correlated with which of these two components. For example, it can easily be seen that morning shifts have a positive loading on this first principal component and the evening and night shifts have a negative loading. However, it is not always easy to give interpretation to the different components. Figure 3 provides visual representation of the relative importance of the shift variable in the two principal components. Here, it becomes clear that the first component indicates the difference in preference between morning shifts (where Thursday and Friday have the highest loading) versus night and evening (only Thursday and Friday evening) shifts. Principal component 2 is more straightforward and shows the difference in preference between evening and night shift (apart from which day of the week it is).

Insert Table 3 about here

Insert Figure 3 about here 
Looking at the individual employees, the component scores (results not shown) give an indication of their preferences. For example, ID 3 has a high score on the first component (2.37) and a moderately low score on the second component (-0.77). This indicates a preference for morning shifts (PC1) and a tendency to prefer night above evening shifts (PC2). With the latter, however, the low sample size and the presence of outliers (permanent night shifts) has to be taken into account. Finally, figure 4 shows the biplot with the two principal components, together with the principal component scores (black ID numbers) and the principal component loadings vectors (arrows).

Insert Figure 4 about here

Employees who are closer in the biplot have more similar predicted pattern of preference for the different shifts. In addition, a few employees can be spotted with a clear preference for night shifts (lower left corner). To give an example for a principal component loading vector, the loading for Wednesday morning on the first component is 0.29 , and its loading on the second component is 0.12 ("Wed: morning" is centered at the point $(0.29,0.12)$; axes not shown). The projection of the employee, i.e. principal component scores, on the vector of a shift variable indicates the predicted preference of the employee on the specific shift. In addition, this graph reconfirms that the first component makes a distinction between morning and night/evening shift, whereas the second component makes a distinction between evening and night shifts. The plot shows a high correlation between the different days per shift, but a low correlation between the different shifts (apart from which day of the week it is).

We can conclude that the matrix of component loadings does not have a simple structure: although a pattern of association between shift variables is revealed, several shift variables correlate with more than one principal component. This makes it difficult to classify shifts that 
load on the same component to certain types or groups of employees. However, it is possible to get a picture of the preference in certain shifts via the two principal components, and this for each individual person.

\section{Cluster analysis}

Using hierarchical clustering and Ward's method, the dendrogram showed a three-cluster solution (cf. Figure 5).

Insert Figure 5 about here

Next, the k-means clustering divided the employees into three distinct groups (cf. Figure 6). The proportion of explained variance by the three clusters is $40.6 \%$. This means that almost half of the variation in shift preference is explained by these clusters. In other words, when employees could make their own schedule, we can see three distinct clusters of individuals with different preferences in shifts. Cluster 1 are employees who prefer morning shifts above night shifts (PC1) and evening shifts above night shifts (PC2). Cluster 2 are people who prefer morning shifts above night shifts (PC1) and (often) night shifts above evening shifts (PC2). Cluster 3 are employees on permanent night shifts. This group can be seen as outliers, given the low sample size $(n=5)$.

Insert Figure 6 about here

\section{Ideal versus Imposed Roster: Differences per Group}

Table 4 provides the descriptive label per cluster. There are no large differences between the clusters with regard to the baseline characteristics. However, Cluster 1 includes a higher number of men ( $\mathrm{n}=6)$ and has a lower mean age (34.67) compared to Cluster 2 and Cluster 3. In addition, the median of the different work attitudes are displayed per cluster and this for the imposed 
versus the nurses' ideal roster. Here, Cluster 1 and Cluster 2 showed a significant higher median autonomy, work-life balance and job satisfaction for the nurses' ideal roster. For Cluster 3, there were no significant results, although a higher median score for autonomy and work-life balance is also obtained for the nurses' ideal roster. However, it should be noted that the Wilcoxon test has little power when the sample size is small $(n \leq 5)$. Finally, no significant results were found for a higher median employer attractiveness score for the nurses' ideal roster, and this for any of the clusters.

Insert Table 4 about here

\section{DISCUSSION}

This pilot study looked at the preferences in shifts for "nurses' ideal roster" and looked at the discrepancy between this ideal roster versus the "imposed roster" via four work attitudes, i.e. autonomy, work-life balance, job satisfaction and employer attractiveness. The focus was on simple descriptive statistics rather than formal hypothesis testing. The results of this pilot study will serve as input for a larger anticipated multicenter study.

First, the results showed a significant difference in the mean score for autonomy, job satisfaction and work-life balance when the nurses' ideal roster would be used compared to the imposed roster. Second, we were able to gain insight into the nurses' preference in shifts and found three groups with similar preferences; i.e. nurses who prefer (1) morning or evening shifts above night shifts (2) morning shifts above night shifts and (often) night shifts above evening shifts (3) permanent night shifts (outliers). Third, there the first two cluster groups showed a significant higher median autonomy, work-life balance and job satisfaction in the case of the nurses' ideal roster. In addition, there were no large differences between the clusters with regard to their personal characteristics. The sample size in the third group was too small to reveal 
significant differences. When reading these results, one should bear in mind limited sample size $(n=58)$ of this pilot study.

These findings confirm the results of previous research that uses flexible work arrangements to give employees more control over their schedule, namely that an increase in autonomy was associated with a better work-life balance, higher job satisfaction and a higher employer attractiveness (Albertsen et al., 2014; Koning, 2014; Mas-Machuca et al., 2016; Onken-Menke et al., 2018; Pryce et al., 2006). This is in line with our expectations, given that it can be expected that the nurses' most ideal roster (as asked in this survey, without regard to any restrictions) will do better than rosters where certain rules or regulations must be taken into account (i.e. flexible work arrangements). Research that assesses the preferences of individual nurses and links these preferences to certain work attitudes is, to the best of our knowledge, non-existent.

\section{Practical Implications and Future Research}

The results of this pilot study give a preliminary insight into the nurses' preference in shifts. This can be helpful as input for computerized healthcare personnel scheduling (e.g., mathematical programming, heuristics and artificial intelligence approaches). Research that uses these methods often ignored the preferences of nurses (Ferland et al., 2001), used a specific preference shift pattern in cyclic scheduling (Dowsland \& Thompson, 2000), or used aggregated preferences from surveys (Azaiez \& Al Sharif, 2005). Individual nurse preferences are seldom incorporated (Berrada, Ferland, \& Michelon, 1996). In addition, this pilot study gives an indication of how satisfied the employees are with their imposed roster, and what a maximum increase of this (or other work attitudes) could be if they would receive or make their ideal roster. This can be interesting when a company wishes to switch to, for example, selfscheduling, where the "final roster" is a compromise between the "nurse's 'ideal roster" and the “imposed roster". This means that employees will almost never receive $100 \%$ their ideal 
schedule as they need to switch shifts among colleagues to meet staffing needs, have to comply to the rules, regulations and guidelines of the organization and, in addition, the monthly recurring process can be seen as a cumbersome procedure (Silvestro \& Silvestro, 2000; Wynendaele, Gemmel, Pattyn, Myny, \& Trybou, 2020).

Future research should explore whether these work attitudes will still increase in the same manner if the "final roster" (that aims a maximum synchronization of the organizational and individual temporal schemata) does not meet the nurses' preferences as well as the "nurses' ideal roster" (i.e. the individual temporal schemata of the employees). In addition, apart from looking at a possible increase in certain work attitudes, it can also be beneficial to test whether are not an organization is ready for an implementation of, for example, self-scheduling (e.g., via readiness for change questionnaires) (Shea, Jacobs, Esserman, Bruce, \& Weiner, 2014).

Furthermore, despite the small sample size, a few groups with similar preferences in shifts were found. This means that different individuals have distinct preferences in shifts. A fixed schedule where the various types of shifts are equally distributed to everyone, will therefore never give a fair outcome for each employee. Future research should elaborate on this, and investigate why certain nurses have different preferences in shifts. For example, various personal characteristics or different life stages can alter ones preferences in shifts. This understanding can aid in making specific predictions about when nurses will or will not entrain (Shipp \& Richardson, 2019).

\section{Theoretical Implications and Future Research}

Though the "nurses' ideal roster" we wanted to gain insight into the nurses individual temporal schemata. On the other hand, the organizational temporal structure was represented by the "imposed roster". Via the differences in work attitudes between these two types of rosters, we aimed to assess how individual nurses responded to the discrepancy between their individual temporal structure versus that of the organization. When there is inconsistency with one's 
temporal schema, employees can automatically or deliberately entrain, actively or passively resist, or create additional temporal structure (Shipp \& Richardson, 2019). For healthcare personnel and in a traditional nursing work environment, we can presume that individuals may deliberately entrain, i.e. entrain to the organization's suggested time line but do so by consciously rationalizing inconsistencies (Shipp \& Richardson, 2019). The 24-hours a day, 7days a week coverage where nurses have to work closely together and must coordinate with others to accomplish mutually dependent goals, creates a situation where nurses feel pressure to entrain, even when this situation does not fit their own temporal schemata (Johns, 2018). By identifying how large the discrepancy is between the "nurses' ideal roster" and the "imposed roster", we want to see how individuals navigate the tension between their own individualized view of time versus the organizational structure. For this, two predictors are needed. First, personal characteristics, as it is possible that certain people are more sensitive to deviations than others. For example, certain stages in life will lead to different priorities. How the imposed roster is in line with these priorities will influence their level of entrainment. Second, the discrepancy between the two rosters, since a large difference can make people less likely to be satisfied. For example, someone that likes to work in the evening that has to work lots of morning shifts. This pilot study only included a limited number of personal characteristics. In future research, extra variables (for example morning- versus evening-type) as well as the discrepancy between the two roosters, should get more attention.

The traditional nursing work environment outlines a situation where employees have little control over resources, decisions, or rewards. Change this situation to an empowering environment where nurses get more control over their working hours, and they are more likely to express their opinions when the timing of a situation is inconsistent with their schemata (Morrison, 2014). This could evoke for example, active resistance, which includes larger efforts to change the organization's temporal structure to match one's personal sense of timing (Shipp 
\& Richardson, 2019). To avoid this, it is necessary to prevent uncertainty as to why certain decision were made (e.g., a request for a particular shift that has been refused).

\section{Limitations}

This first exploratory pilot study already indicates that an "ideal" schedule that fully responds to the needs of the nurses can lead to better work attitudes, and that groups of people exist with differences in shift preferences. However, this study has also some limitations.

First, given that the data on the work attitudes for both the "nurses' ideal roster" and the "imposed roster" are collected from the same respondents at one point in time, this can lead to potential common method bias. However, we did try to anticipate this through physically separating the two rosters and their associated work attitudes and by ensuring anonymity (Podsakoff, MacKenzie, Lee, \& Podsakoff, 2003).

Second, this pilot study has a relatively small sample size. Although mainly simple descriptive statistics are used, a larger sample size in needed to minimize the probability of errors, maximize the accuracy of population estimates, and increase the generalizability of the results. Although different opinions exist on the sample size for principal component analysis, the best results can be expected when the number of subjects and subject to variable ratio are both large (Osborne \& Costello, 2004). In addition, making a meaningful clustering is an iterative process and a larger sample size will allow to check the stability of the cluster solution (Everitt \& Hothorn, 2011). In the foreseen larger anticipated study, hypothesis testing will be possible and multilevel analysis should be used (employees nested within departments, departments nested within hospitals) where we can assume that outcomes within a cluster are correlated and outcomes belonging to different clusters are independent.

Finally, the "nurses' ideal roster" does not take into account any restrictions. This is a simplified and an unrealistic representation of the reality, given that a nurse may be planning too many shifts one after another. This, for example, could be in violation of the law and could have a 
negative impact on his or her health. However, given that these nurses have typically been working in this context for a long time, we could assume that some of these rules have been incorporated or internalized. Finally, future research should integrate the degree to which one shift was preferred over another.

\section{CONCLUSION}

There is a significant difference in the mean autonomy, job satisfaction and work-life balance between the data in case of the ideal and the imposed roster, which indicate that there is room for improvement for these work attitudes by working with a personalized schedule. In addition, three different groups with similar preferences in shifts could be extracted. Here, again, there was a significant difference in the median autonomy, job satisfaction and work-life balance between the ideal and the imposed roster, for two of the three groups. The interpretation of these results should bear in mind that this pilot study had a small sample size. Future research should further focus on identifying the individual preferences in shifts, on the discrepancy between the individual and the organizational schemata and what the effect is on different work attitudes. Furthermore, it should be explored to what extent self-scheduling coincides with the ideal schedule to guide healthcare management in their decision to implement this method. 


\section{REFERENCES}

Abernathy, W. J., Baloff, N., Hershey, J. C., \& Wandel, S. (1973). A three-stage manpower planning and scheduling model-a service-sector example. Operations Research, 21(3), 693-711.

Aiken, L. H., Clarke, S. P., Sloane, D. M., Sochalski, J., \& Silber, J. H. (2002). Hospital nurse staffing and patient mortality, nurse burnout, and job dissatisfaction. Jama, 288(16), 1987-1993.

Aiken, L. H., Sermeus, W., Van den Heede, K., Sloane, D. M., Busse, R., McKee, M., . . MorenoCasbas, M. T. (2012). Patient safety, satisfaction, and quality of hospital care: cross sectional surveys of nurses and patients in 12 countries in Europe and the United States. Bmj, 344, e1717.

Aiken, L. H., Sloane, D. M., Bruyneel, L., Van den Heede, K., Griffiths, P., Busse, R., . . Lesaffre, E. (2014). Nurse staffing and education and hospital mortality in nine European countries: a retrospective observational study. The Lancet, 383(9931), 1824-1830.

Albertsen, K., Garde, A. H., Nabe-Nielsen, K., Hansen, Å. M., Lund, H., \& Hvid, H. (2014). Worklife balance among shift workers: results from an intervention study about self-rostering. International Archives of Occupational and Environmental Health, 87(3), 265-274. doi:10.1007/s00420-013-0857-x.

Albertsen, K., Rafnsdóttir, G. L., Grimsmo, A., Tómasson, K., \& Kauppinen, K. (2008). Workhours and worklife balance. SJWEH Supplements(5), 14-21.

Ancona, D., \& Chong, C.-L. (1996). Entrainment: Pace, cycle, and rhythm in organizational behavior. RESEARCH IN ORGANIZATIONAL BEHAVIOR, VOL 18, 1996, 18, 251-284.

Ancona, D., \& Waller, M. J. (2007). The dance of entrainment: Temporally navigating across multiple pacers. Research in Sociology of Work, 17, 115.

Asgeirsson, E. I. (2014). Bridging the gap between self schedules and feasible schedules in staff scheduling. Annals of Operations Research, 218(1), 51-69. doi:10.1007/s10479-012-1060-2

Azaiez, M. N., \& Al Sharif, S. S. (2005). A 0-1 goal programming model for nurse scheduling. Computers \& Operations Research, 32(3), 491-507. doi:10.1016/s0305-0548(03)00249-1

Bard, J. F., \& Purnomo, H. W. (2005). Preference scheduling for nurses using column generation. European Journal of Operational Research, 164(2), 510-534. doi:10.1016/j.ejor.2003.06.046

Berrada, I., Ferland, J. A., \& Michelon, P. (1996). A multi-objective approach to nurse scheduling with both hard and soft constraints. Socio-Economic Planning Sciences, 30(3), 183-193.

Blau, P. (1964). Power and exchange in social life. In: New York: J Wiley \& Sons.

Boamah, S. A., Read, E. A., \& Spence Laschinger, H. K. (2017). Factors influencing new graduate nurse burnout development, job satisfaction and patient care quality: a time-lagged study. $J$ Adv Nurs, 73(5), 1182-1195.

Burbidge, J. B., Magee, L., \& Robb, A. L. (1988). Alternative Transformations to Handle Extreme Values of the Dependent Variable. Journal of the American Statistical Association, 83(401), 123-127. doi:10.1080/01621459.1988.10478575

Burke, E. K., De Causmaecker, P., Berghe, G. V., L, V., \& eghem, H. (2004). The state of the art of nurse rostering. Journal of Scheduling, 7(6), 441-449.

Cline, D., Reilly, C., \& Moore, J. F. (2003). What's behind RN turnover? Nurs Manage, 34(10), 5053.

Cropanzano, R., \& Mitchell, M. S. (2005). Social exchange theory: An interdisciplinary review. Journal of Management, 31(6), 874-900.

Dolbier, C. L., Webster, J. A., McCalister, K. T., Mallon, M. W., \& Steinhardt, M. A. (2005). Reliability and validity of a single-item measure of job satisfaction. American Journal of Health Promotion, 19(3), 194-198.

Dowsland, K. A., \& Thompson, J. M. (2000). Solving a nurse scheduling problem with knapsacks, networks and tabu search. Journal of the Operational Research Society, 51(7), 825-833.

Eby, L. T., Casper, W. J., Lockwood, A., Bordeaux, C., \& Brinley, A. (2005). Work and family research in IO/OB: Content analysis and review of the literature (1980-2002). Journal of Vocational Behavior, 66(1), 124-197. doi:https://doi.org/10.1016/j.jvb.2003.11.003 
Ernst, A. T., Jiang, H., Krishnamoorthy, M., \& Sier, D. (2004). Staff scheduling and rostering: A review of applications, methods and models. European Journal of Operational Research, 153(1), 3-27. doi:10.1016/s0377-2217(03)00095-x

Everitt, B., \& Hothorn, T. (2011). An introduction to applied multivariate analysis with R: Springer Science \& Business Media.

Ferland, J. A., Berrada, I., Nabli, I., Ahiod, B., Michelon, P., Gascon, V., \& Gagné, É. (2001). Generalized assignment type goal programming problem: Application to nurse scheduling. Journal of Heuristics, 7(4), 391-413.

Glette, M. K., Aase, K., \& Wiig, S. (2017). The relationship between understaffing of nurses and patient safety in hospitals-A literature review with thematic analysis.

Jeffrey Hill, E., Grzywacz, J. G., Allen, S., Blanchard, V. L., Matz-Costa, C., Shulkin, S., \& PittCatsouphes, M. (2008). Defining and conceptualizing workplace flexibility. Community, Work and Family, 11(2), 149-163.

Johns, G. (2018). Advances in the treatment of context in organizational research. Annual Review of Organizational Psychology and Organizational Behavior, 5, 21-46.

Khoong, C. M. (1996). An integrated system framework and analysis methodology for manpower planning. International Journal of Manpower.

Koning, C. (2014). Does self-scheduling increase nurses' job satisfaction? An integrative literature review. Nurs Manage, 21(6), 24-28. doi:10.7748/nm.21.6.24.e1230

Lancaster, G. A., Dodd, S., \& Williamson, P. R. (2004). Design and analysis of pilot studies: recommendations for good practice. J Eval Clin Pract, 10(2), 307-312. doi:https://doi.org/10.1111/j..2002.384.doc.x

Le, S., Josse, J., \& Husson, F. (2008). FactoMineR: An R Package for Multivariate Analysis. Journal of Statistical Software, 25(1), 1-18. doi:10.18637/jss.v025.i01

Mas-Machuca, M., Berbegal-Mirabent, J., \& Alegre, I. (2016). Work-life balance and its relationship with organizational pride and job satisfaction. Journal of Managerial Psychology.

McGrath, J. E., \& Kelly, J. R. (1986). Time and human interaction: Toward a social psychology of time: Guilford Press.

McGrath, J. E., Kelly, J. R., \& Machatka, D. E. (1984). The social psychology of time: Entrainment of behavior in social and organizational settings. Applied social psychology annual.

McGrath, J. E., \& Rotchford, N. L. (1983). Time and behavior in organizations. Research in organizational behavior.

Morrison, E. W. (2014). Employee voice and silence. Annu. Rev. Organ. Psychol. Organ. Behav., l(1), 173-197.

Nguyen Huy, Q. (2001). Time, temporal capability, and planned change. Academy of Management Review, 26(4), 601-623.

Nguyen, L. H., \& Holmes, S. (2019). Ten quick tips for effective dimensionality reduction. PLoS Comput Biol, 15(6), e1006907. doi:10.1371/journal.pcbi.1006907

Onken-Menke, G., Nüesch, S., \& Kröll, C. (2018). Are you attracted? Do you remain? Meta-analytic evidence on flexible work practices. Business Research, 11(2), 239-277. doi:10.1007/s40685017-0059-6

Osborne, J. W., \& Costello, A. B. (2004). Sample size and subject to item ratio in principal components analysis. Practical Assessment, Research, and Evaluation, 9(1), 11.

Perlow, L. A. (1999). The time famine: Toward a sociology of work time. Administrative science quarterly, 44(1), 57-81.

Podsakoff, P. M., MacKenzie, S. B., Lee, J.-Y., \& Podsakoff, N. P. (2003). Common method biases in behavioral research: a critical review of the literature and recommended remedies. Journal of Applied Psychology, 88(5), 879.

Pryce, J., Albertsen, K., \& Nielsen, K. (2006). Evaluation of an open-rota system in a Danish psychiatric hospital: a mechanism for improving job satisfaction and work-life balance. $J$ Nurs Manag, 14(4), 282-288. doi:10.1111/j.1365-2934.2006.00617.x

Ronnberg, E., \& Larsson, T. (2010). Automating the self-scheduling process of nurses in Swedish healthcare: a pilot study. Health Care Manag Sci, 13(1), 35-53. doi:10.1007/s10729-0099107-x 
Ryan, R. M., \& Deci, E. L. (2000). Self-determination theory and the facilitation of intrinsic motivation, social development, and well-being. American psychologist, 55(1), 68.

Shea, C. M., Jacobs, S. R., Esserman, D. A., Bruce, K., \& Weiner, B. J. (2014). Organizational readiness for implementing change: a psychometric assessment of a new measure. Implementation Science, 9(1), 7.

Shipp, A. J., \& Richardson, H. (2019). The Impact of Temporal Schemata: Understanding When Individuals Entrain versus Resist or Create Temporal Structure. Academy of Management $\operatorname{Review}(\mathrm{ja})$.

Silvestro, R., \& Silvestro, C. (2000). An evaluation of nurse rostering practices in the National Health Service. J Adv Nurs, 32(3), 525-535.

Storey, C., Cheater, F., Ford, J., \& Leese, B. (2009). Retention of nurses in the primary and community care workforce after the age of 50 years: database analysis and literature review. $J$ Adv Nurs, 65(8), 1596-1605. doi:10.1111/j.1365-2648.2009.05036.x

Venkataraman, R., \& Brusco, M. J. (1996). An integrated analysis of nurse staffing and scheduling policies. Omega, 24(1), 57-71.

Wren, A. (1995). Scheduling, timetabling and rostering - a special relationship? Paper presented at the International conference on the practice and theory of automated timetabling.

Wynendaele, H., Gemmel, P., Pattyn, E., Myny, D., \& Trybou, J. (2020). Systematic review: What is the impact of self-scheduling on the patient, nurse and organization? J Adv Nurs. doi:10.1111/jan.14579

Wynendaele, H., Willems, R., \& Trybou, J. (2019). Systematic review: Association between the patient-nurse ratio and nurse outcomes in acute care hospitals. J Nurs Manag, 27(5), 896-917. doi:10.1111/jonm.12764 


\section{TABLES AND FIGURES}

\section{Tables}

Table 1: employee's characteristics $(n=58)$

$\begin{array}{ccc}\text { Full- } & & \\ \text { time } & \text { Part-time } & \text { Overall } \\ (n=32) & (n=25) & (n=58)\end{array}$

\section{Gender}

Female $24(75 \%) \quad 24(96 \%) \quad 49(84 \%)$

Male

$8(25 \%) \quad 1(4 \%) \quad 9(16 \%)$

\section{Marital status}

Married/living together $\quad 20(63 \%) \quad 21(84 \%) \quad 41(71 \%)$

Divorced/single $\quad 11(34 \%) \quad 4(16 \%) \quad 15(26 \%)$

$\begin{array}{llll}\text { Missing } & 1(3 \%) & 0(0 \%) & 2(3 \%)\end{array}$

\section{Children}

Yes

$10(31 \%) \quad 18(72 \%) \quad 28(48 \%)$

No

$18(56 \%) \quad 2(8 \%) \quad 20(34 \%)$

Missing

$4(13 \%) \quad 5(20 \%) \quad 10(17 \%)$

\section{Function}

Nurse

$27(84 \%) \quad 20(80 \%) \quad 48(83 \%)$

Midwife

$4(12 \%) \quad 5(20 \%) \quad 9(16 \%)$

Missing

$1(3 \%) \quad 0(0 \%) \quad 1(2 \%)$

Age

Mean (SD)

$33( \pm 9.1) \quad 41( \pm 9.8) \quad 36( \pm 10)$

Missing

$2(6 \%) \quad 6(24 \%) \quad 8(14 \%)$ 
Table 2: Mean difference in work attitudes between the imposed roster versus the nurses' ideal roster ( $\mathrm{n}=58$ )

\begin{tabular}{|c|c|c|c|c|c|}
\hline \multicolumn{6}{|c|}{ In the context of } \\
\hline & imposed roster & nurses' ideal roster & $\begin{array}{c}\text { Mean difference } \\
(95 \% \mathrm{CI})\end{array}$ & $\begin{array}{c}\text { t-statistic } \\
\text { (df) }\end{array}$ & P-value* \\
\hline \multicolumn{6}{|l|}{ Autonomy } \\
\hline Mean (sd) & $3.2( \pm 0.80)$ & $3.9( \pm 0.77)$ & $0.67(0.45$ to 0.90$)$ & $6.01(55)$ & $<0.01$ \\
\hline Missing & $2(3.4 \%)$ & $0(0 \%)$ & & & \\
\hline \multicolumn{6}{|l|}{ Work-life balance } \\
\hline Mean (sd) & $3.5( \pm 0.56)$ & $4.0( \pm 0.48)$ & $0.55(0.37$ to 0.73$)$ & $6.08(51)$ & $<0.01$ \\
\hline Missing & $2(3.4 \%)$ & $4(6.9 \%)$ & & & \\
\hline \multicolumn{6}{|l|}{ Job satisfaction } \\
\hline Mean (sd) & $7.8( \pm 1.5)$ & $8.4( \pm 1.6)$ & $0.60(0.39$ to 0.81$)$ & $5.85(54)$ & $<0.01$ \\
\hline Missing & $2(3.4 \%)$ & $2(3.4 \%)$ & & & \\
\hline \multicolumn{6}{|l|}{ Employer attractiveness } \\
\hline Mean (sd) & $3.9( \pm 0.54)$ & $4.1( \pm 0.49)$ & $0.16(0.01$ to 0.30$)$ & $2.18(54)$ & $<0.03$ \\
\hline Missing & $1(1.7 \%)$ & $2(3.4 \%)$ & & & \\
\hline
\end{tabular}

Note: $\mathrm{sd}=$ standard deviation

* Student's paired t-test with Bonferroni correction for mulitple t-test $(0.05 / 4)=0.012$ 
Table 3: per shift variable: mean (sd), component loadings for two PCs; per principal component: how much variance each component explains in the data

\section{Mean (sd) $\quad$ PC 1 $\quad$ PC 2}

\section{Per shift}

\begin{tabular}{|c|c|c|c|c|}
\hline Monday & Morning & $1.38(1.29)$ & 0.34 & -0.02 \\
\hline & Evening & $0.79(1.01)$ & -0.12 & 0.33 \\
\hline & Night & $0.29(0.35)$ & -0.15 & -0.23 \\
\hline Tuesday & Morning & $1.74(1.25)$ & 0.35 & 0.04 \\
\hline & Evening & $0.86(0.89)$ & -0.16 & 0.37 \\
\hline & Night & $0.36(0.38)$ & -0.17 & -0.23 \\
\hline Wednesday & Morning & $1.60(1.47)$ & 0.29 & 0.12 \\
\hline & Evening & $0.67(0.79)$ & -0.15 & 0.28 \\
\hline & Night & $0.38(0.38)$ & -0.18 & -0.24 \\
\hline Thursday & Morning & $1.71(1.40)$ & 0.39 & 0.04 \\
\hline & Evening & $0.95(1.07)$ & -0.20 & 0.40 \\
\hline & Night & $0.34(0.37)$ & -0.19 & -0.22 \\
\hline Friday & Morning & $1.33(1.45)$ & 0.36 & 0.00 \\
\hline & Evening & $0.84(0.98)$ & -0.21 & 0.32 \\
\hline & Night & $0.28(0.34)$ & -0.17 & -0.21 \\
\hline Saturday & Morning & $0.59(0.53)$ & 0.14 & 0.00 \\
\hline & Evening & $0.45(0.50)$ & -0.09 & 0.15 \\
\hline & Night & $0.26(0.34)$ & -0.15 & -0.22 \\
\hline Sunday & Morning & $0.52(0.50)$ & 0.15 & -0.01 \\
\hline & Evening & $0.53(0.57)$ & -0.07 & 0.15 \\
\hline & Night & $0.26(0.34)$ & -0.16 & -0.21 \\
\hline \multicolumn{5}{|l|}{ Per principal component } \\
\hline Eigenvalue & & & 2.15 & 1.69 \\
\hline Variance $\%$ & & & 30.72 & 24.22 \\
\hline Cumulative variance $\%$ & & & 30.72 & 54.94 \\
\hline
\end{tabular}

Note: $\mathrm{sd}=$ standard deviation, $\mathrm{PC}=$ principal component 
Table 4: Cluster profiles with comparison of work attitudes in the context of "imposed roster" versus "nurses' ideal roster"

\begin{tabular}{|c|c|c|c|}
\hline & Cluster 1 & Cluster 2 & Cluster 3 \\
\hline Cluster size (n) & 29 & 24 & 5 \\
\hline Descriptive label $\sim$ preferred shift & $\begin{array}{c}\text { Morning shifts above night } \\
\text { shifts (PC1) and evening } \\
\text { shifts above night shifts } \\
\text { (PC2) }\end{array}$ & $\begin{array}{l}\text { Morning shifts above night } \\
\text { shifts (PC1) and (often) } \\
\text { night shifts above evening } \\
\text { shifts (PC2) }\end{array}$ & $\begin{array}{c}\text { Permanent night shifts } \\
\text { (outliers) }\end{array}$ \\
\hline Age $($ mean $(\mathrm{sd}))$ & $34.67(9.4)$ & $37.65(11.17)$ & $37.40(10.90)$ \\
\hline Women (n (\%)) & $23(79 \%)$ & $22(92 \%)$ & $4(80 \%)$ \\
\hline \multicolumn{4}{|l|}{ Work time (n (\%)) } \\
\hline Full-time & $16(55 \%)$ & $13(54 \%)$ & $2(40 \%)$ \\
\hline Part-time & $11(38 \%)$ & $10(42 \%)$ & $3(60 \%)$ \\
\hline Missing & $2(7 \%)$ & $1(4 \%)$ & $0(0 \%)$ \\
\hline \multicolumn{4}{|l|}{ Marital status (n (\%)) } \\
\hline Married/living together with children & $10(34 \%)$ & $8(33 \%)$ & $3(60 \%)$ \\
\hline Married/living together without children & $7(24 \%)$ & $4(17 \%)$ & $1(20 \%)$ \\
\hline Divorced/ single with children & $3(10 \%)$ & $3(13 \%)$ & $0(0 \%)$ \\
\hline Divorced/ single without children & $4(14 \%)$ & $2(8 \%)$ & $1(20 \%)$ \\
\hline Missing & $5(17 \%)$ & $7(29 \%)$ & $0(0 \%)$ \\
\hline
\end{tabular}




\section{Cluster 1}

\section{Difference* in work}

attitudes

\begin{tabular}{|c|c|c|c|c|c|c|c|c|c|}
\hline & \multicolumn{3}{|c|}{ Nurses’ } & \multicolumn{3}{|c|}{ Nurses' } & \multicolumn{3}{|c|}{ Nurses’ } \\
\hline & $\begin{array}{l}\text { Imposed } \\
\text { roster }\end{array}$ & $\begin{array}{l}\text { ideal } \\
\text { roster }\end{array}$ & $\begin{array}{c}\mathrm{p}- \\
\text { value }{ }^{* *}\end{array}$ & $\begin{array}{l}\text { Imposed } \\
\text { roster }\end{array}$ & $\begin{array}{l}\text { ideal } \\
\text { roster }\end{array}$ & $\begin{array}{c}\mathrm{p}- \\
\text { value } * *\end{array}$ & $\begin{array}{l}\text { Imposed } \\
\text { roster }\end{array}$ & $\begin{array}{l}\text { ideal } \\
\text { roster }\end{array}$ & $\begin{array}{c}\mathrm{p}- \\
\text { value }^{* *}\end{array}$ \\
\hline Autonomy & $3.33(1.17)$ & $4.00(0.67)$ & $<0.01$ & $3.17(1.00)$ & $4.00(0.67)$ & $<0.01$ & $3.33(2.33)$ & $4.00(1.00)$ & 0.05 \\
\hline Work-life balance & $3.71(0.57)$ & $4.00(0.43)$ & $<0.01$ & $3.43(0.79)$ & $4.00(0.29)$ & $<0.01$ & $3.14(0.43)$ & $3.79(0.61)$ & 0.09 \\
\hline Employer attractiveness & $4.00(0.30)$ & $4.00(0.60)$ & 0.35 & $4.00(0.60)$ & $4.00(0.60)$ & 0.04 & $4.00(0.40)$ & $4.00(0.20)$ & 0.21 \\
\hline
\end{tabular}

Note: sd = standard deviation

* median (interquartile range)

** Wilcoxon one-tailed signed rank test (very small sample size or Shapiro-Wilk normality test showed non-normality) with

Bonferroni correction for multiple testing $(0.05 / 12)=0.0042$ 


\section{Figures}

Figure 1: Conceptual model and hypothesized relationships

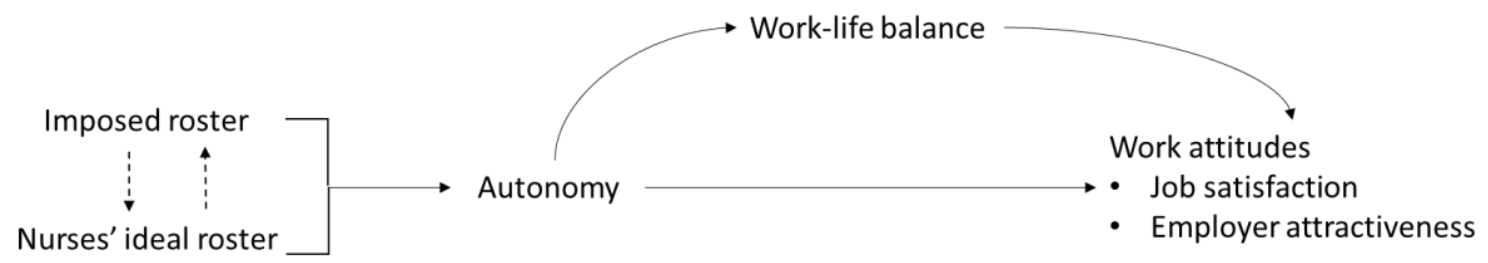

Figure 2: Scree plot (applied to standardized variables) shows an elbow at three components (meaning two components should be retained), Kaiser's rule makes the same conclusion

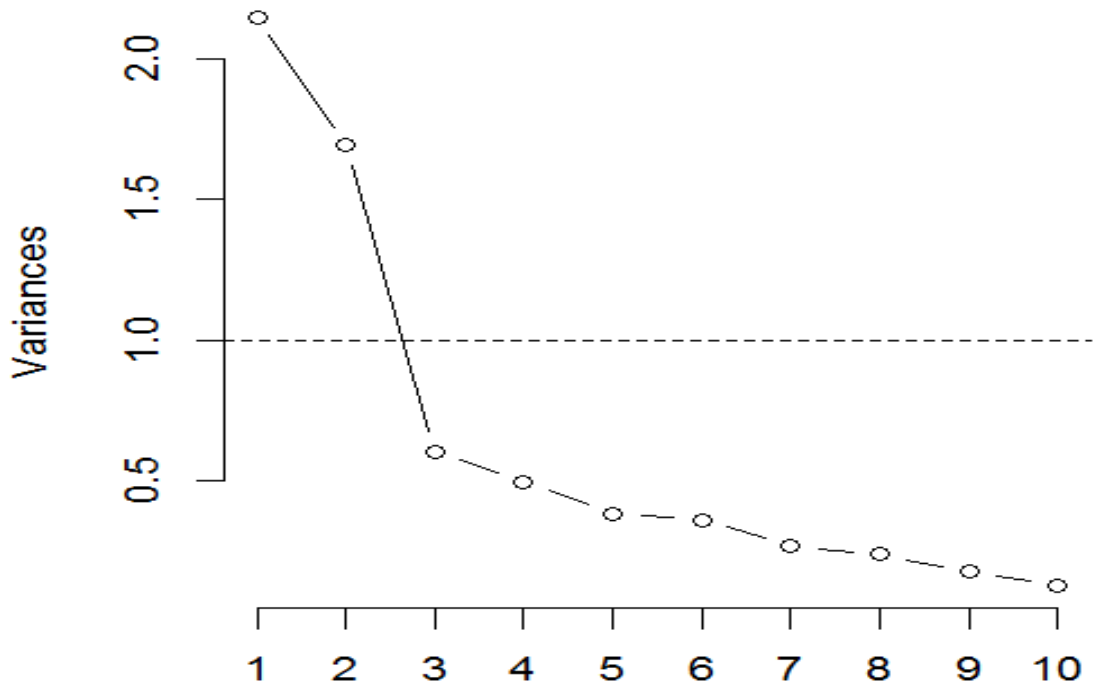


Figure 3: Sources of variation in scheduling by the employees for the two principal components (PC)

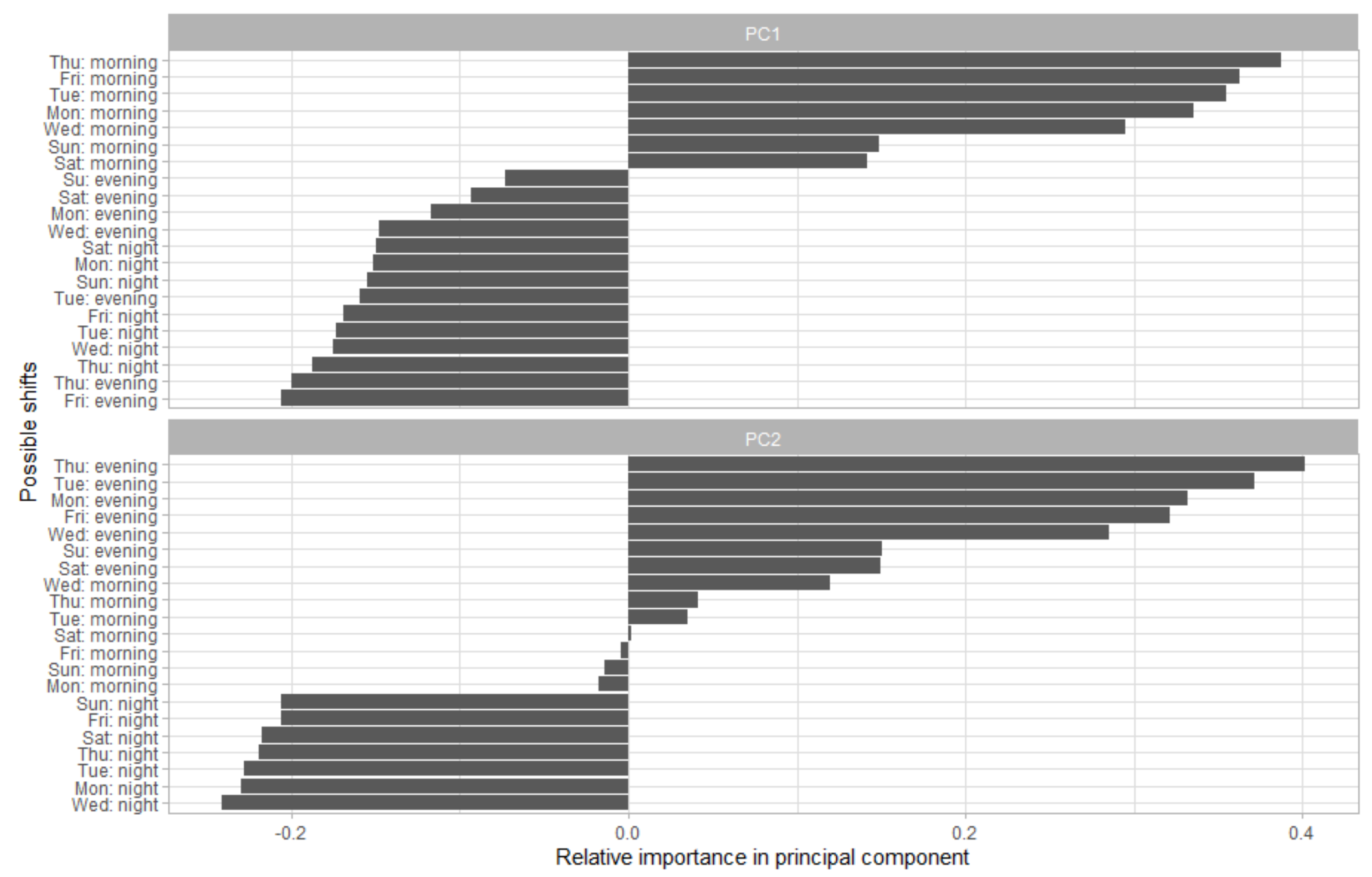


Figure 4: The biplot shows that the first component makes a distinction between morning and evening/night shift, whereas the second component makes a distinction between evening and night shifts.

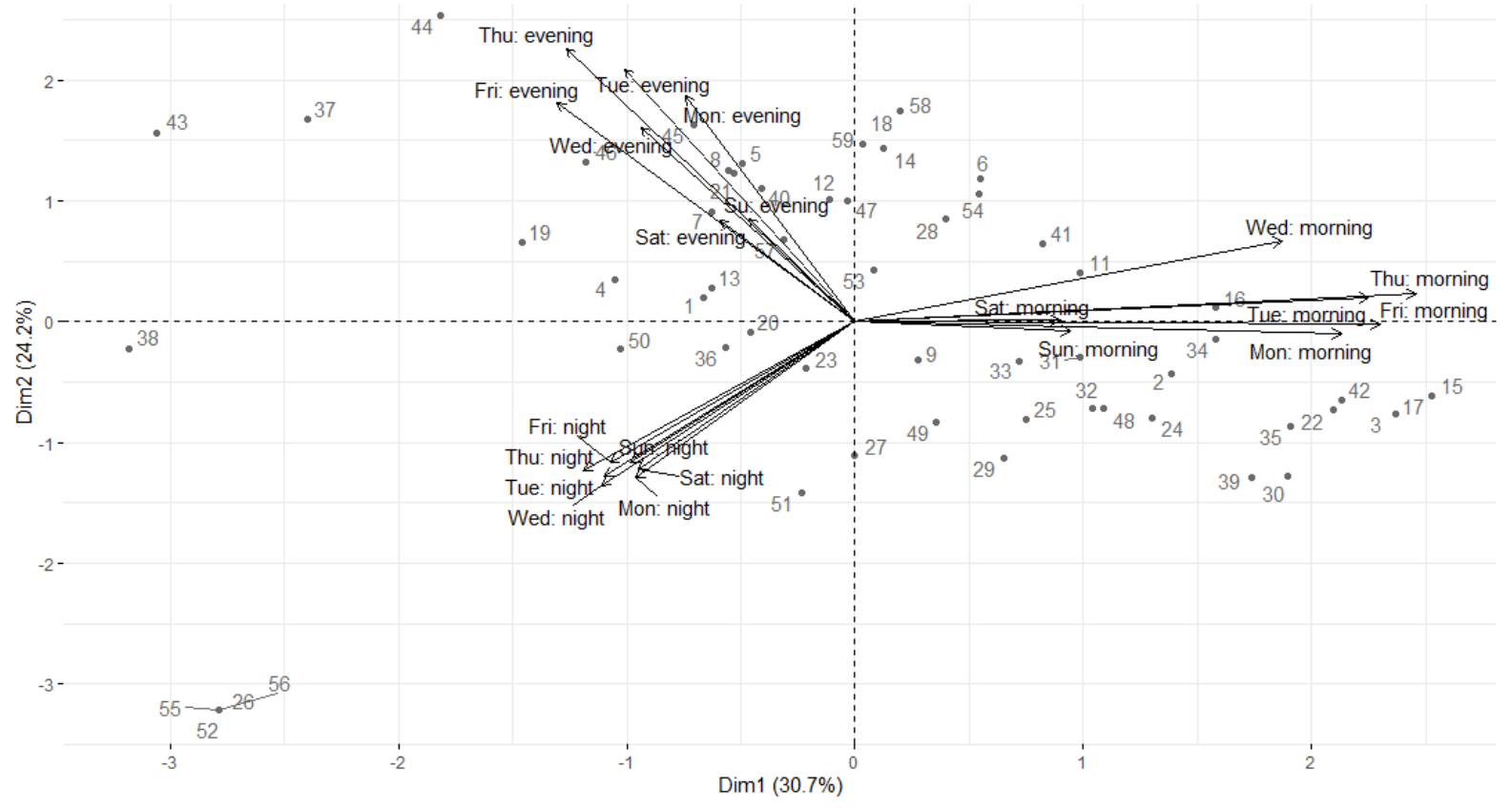

Figure 5: Dendrogram using Ward's method reveals three clusters

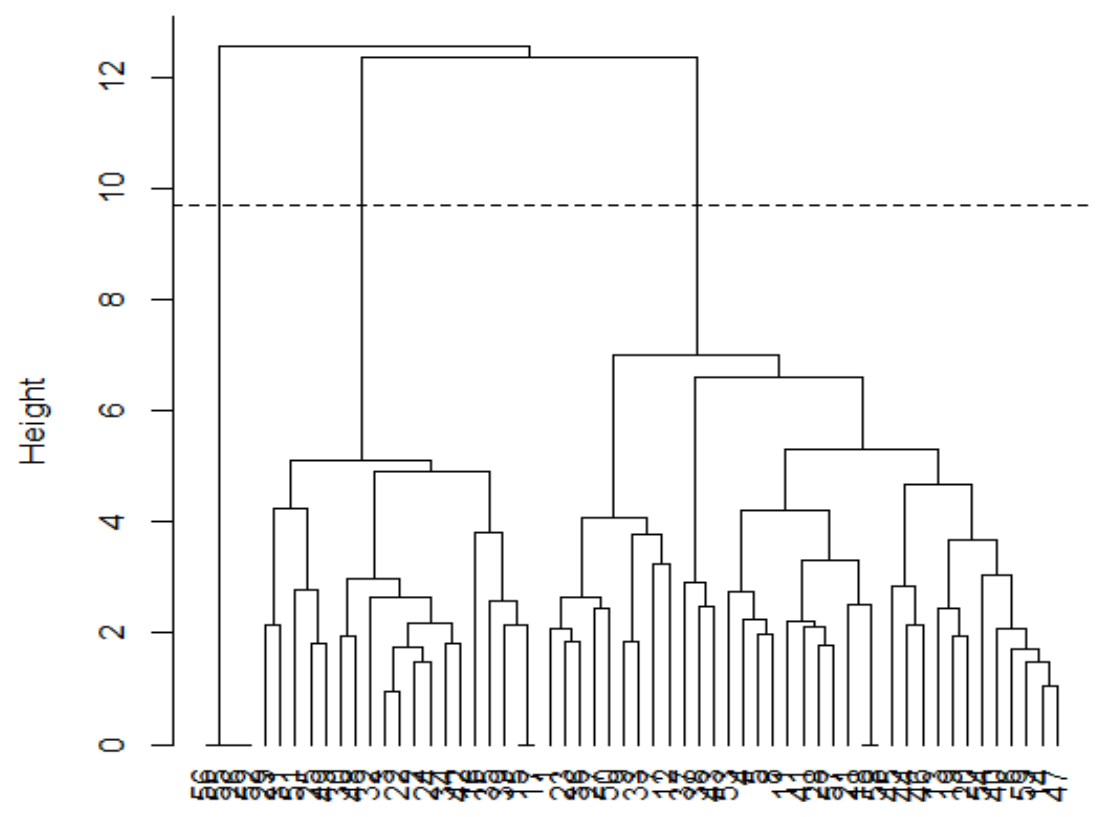


Figure 6: k-means clustering divided the employees into three distinct groups

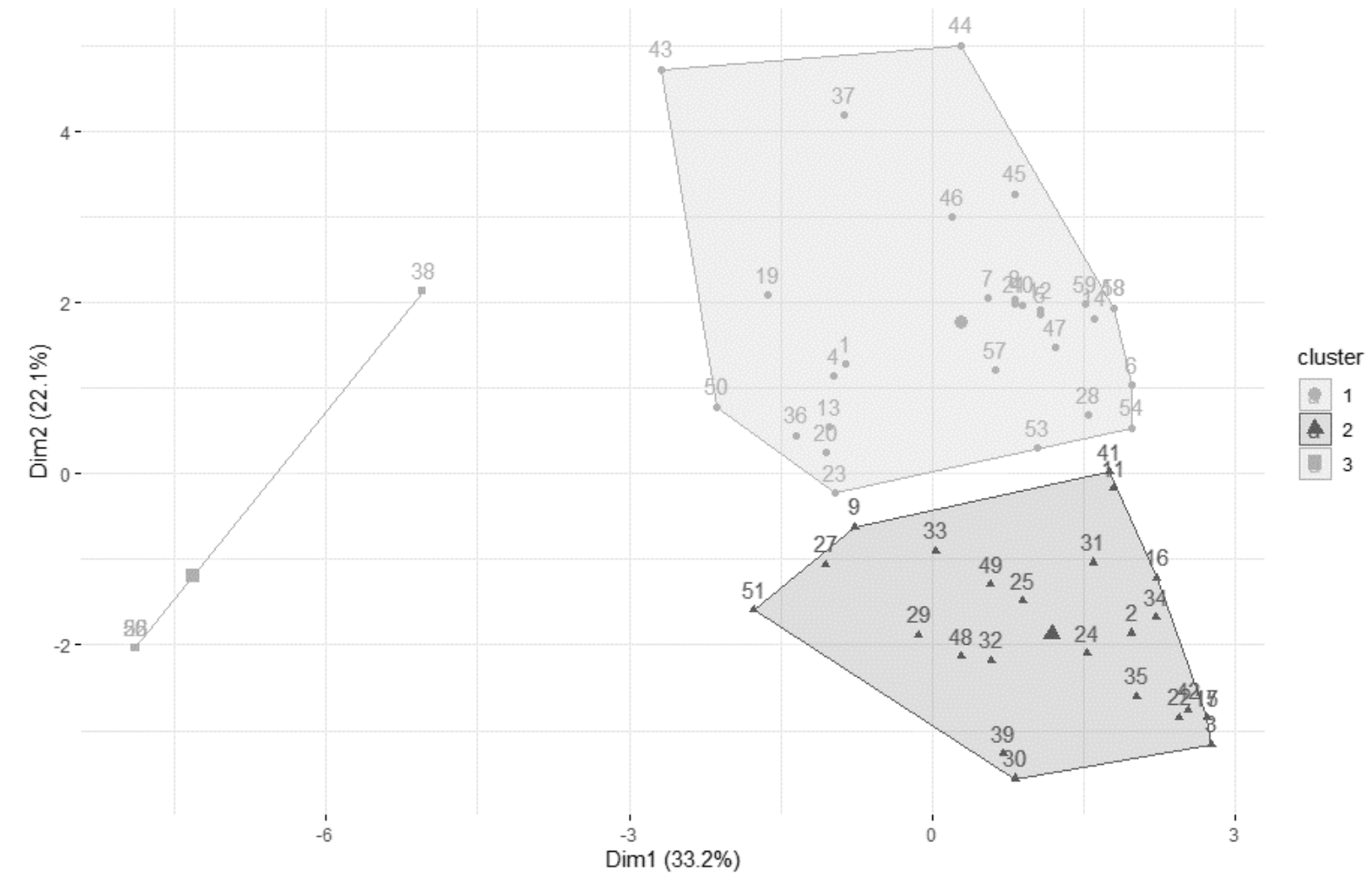

